\title{
HISTOCHEMISTRY OF THE RETINA IN THE ALLOXAN-DIABETIC RAT*
}

\author{
BY \\ FRANK W. NEWELL \\ AND \\ SHINJI KURIMOTO†
}

From the Eye Research Laboratories, University of Chicago, Illinois

THERE have been relatively few studies of the carbohydrate metabolism of the retina of the alloxan-diabetic animal and not all have been in agreement. Illing and Gray (1951) described an impairment of glucose utilization in the retina of diabetic rabbits, but these results were not confirmed by Kornblueth, Yardeni-Yaron, and Wertheimer (1953).

DeRoetth and Pei (1960), using manometric techniques, found decreased anaerobic glycolysis and increased succinic dehydrogenase activity in the retina of alloxan-diabetic rats compared with normal controls. Heath, Rutter and Beck (1962) demonstrated an increase in the nicotinamide-adenine nucleotide content of the alloxan-diabetic rat and a decrease in the reduced form of this nucleotide.

Kurimoto and Newell (1963), using histochemical techniques, have shown an increased phosphorylase activity in the alloxan-diabetic rat retina. Additionally, retinal and renal glycogen which was not mobilized by starvation as was liver glycogen was demonstrated.

It was the purpose of this study to investigate histochemically some of the pathways of glucose metabolism in the normal and the alloxan-diabetic rat. The metabolic pathways of the retina may be studied by means of enzymatic, micro-enzymatic, or histochemical techniques. The usual enzymatic techniques involve the incubation of large segments of the retina with appropriate substrates and measurement of the amount of oxygen used or metabolic products formed. The micro-enzymatic method, as developed by Lowry, Roberts, and Lewis (1956) and Lowry, Roberts, Schulz, Clow, and Clark (1961) provides the most accurate quantitative estimate of enzyme activity in the retina, but permits study solely of one individual layer at a time. Histochemical techniques provide a visualization of a cross-section of the distribution of an enzyme system. These latter techniques, however, depend upon interaction of more than one enzyme and during incubation enzymes may diffuse into adjacent retinal layers so that specific localization enzyme may not be accurate. * This study was supported in part by a grant from the L. B. and E. M. Kuppenheimer Foundation and the USPHS
Sensory Disease Programme Project grant No. NB-03358.

Read at a joint meeting of the Irish Ophthalmological Society and British Diabetic Association, April 26, 1963,

Dublin, Ireland.
+ Fight-for-Sight Fellow financed by the Bob Hope Fight-for-Sight Fund of the National Council to Combat Blindness.
596 


\section{Technique}

Male albino Sprague-Dawley rats weighing between 312 and 355 g. received $20 \mathrm{mg}$. alloxan per $100 \mathrm{~g}$. body weight subcutaneously and were killed 3 to 7 months later. The rats were fed a standard Purina rat chow; insulin was not administered. An equal number of untreated animals was kept for the same period as controls.

The alloxan-diabetic rat urine was repeatedly positive for reducing substance. On the day of killing the diabetic rats weighed between 156 and $180 \mathrm{~g}$., the blood glucose levels were 518 to $690 \mathrm{mg} . / 100 \mathrm{ml}$., and cataracts were present in each animal. The control rats weighed 560 to $620 \mathrm{~g}$., the blood glucose levels were 72 to $90 \mathrm{mg}$. $/ 100 \mathrm{ml}$., and no cataracts were present.

The animals were anaesthetized with ether, and the eyes enucleated, sectioned at the equator, and the vitreous removed. The posterior half of the eye was immersed in a solution of isopentane at a temperature of $-70^{\circ} \mathrm{C}$. The freshlyfrozen tissues were sectioned with a cryostat at $-20^{\circ} \mathrm{C}$. and mounted on cover slips. The sections were then placed in the appropriate incubating medium for one hour at $37^{\circ} \mathrm{C}$. They were then treated in 10 per cent. formol saline for $10 \mathrm{~min}$. and 15 per cent. ethanol for $5 \mathrm{~min}$., successively and mounted in glycerin jelly. Retinae from normal rats of the same age were treated similarly, and liver, kidney, heart, ocular recti muscle, and diaphragm were similarly studied.

Studies were carried out to demonstrate lactic, succinic, and malic dehydrogenase and DPN diaphorase, using appropriate substrates and nitro-blue tetrazolium reductase activity. Control studies were carried out on parallel sections omitting the substrate.

The media used for determination of lactic or malic dehydrogenase contained: $0.1 \mathrm{mM}$. L-malic acid $\mathrm{pH} 7.4$ or $0.1 \mathrm{mM}$. sodium DL-lactate $\mathrm{pH} 7.4 ; 5 \mathrm{mg}$. DPN; $0.01 \mathrm{mM}$. sodium cyanide pH $7.2 ; 0.05 \mathrm{mM}$. magnesium chloride; $0.02 \mathrm{mM}$. phosphate buffer $\mathrm{pH} 7.4 ; 2.5 \mathrm{mg}$. Nitro-BT; $750 \mathrm{mg}$. polyvinyl pyrrolidone; and distilled water to yield a final volume of $10 \mathrm{ml}$.

The succinic dehydrogenase media contained $0.25 \mathrm{mM}$. phosphate buffer pH 7.6; 0.25 mM. sodium succinate; $5 \mathrm{mg}$. Nitro-BT; and distilled water to yield a final volume of $10 \mathrm{ml}$.

The DPN diaphorase solution contained $0.2 \mathrm{mM}$. sodium DL-lactate; $9 \mathrm{mg}$. lactate dehydrogenase; $5 \mathrm{mg}$. DPN; $5 \mathrm{mg}$. Nitro-BT; $0.6 \mathrm{mM}$. phosphate buffer $\mathrm{pH} \mathrm{7.4;} 750 \mathrm{mg}$. polyvinyl pyrrolidone; and distilled water to yield a final volume of $10 \mathrm{ml}$.

In the study of the uridine diphosphate glucose (UDPG) glycogen transferase system, portions of the whole retina were placed in an incubating solution for 3 to 6 hours at $37^{\circ} \mathrm{C}$. The media contained $10 \mathrm{mg}$. UDPG; $2 \mathrm{mg}$. glucose 6-phosphate; $4 \mathrm{mg}$. ethylenediaminetetraacetate; $0.12 \mathrm{mM}$. tris buffer $\mathrm{pH} 7.4 ; 0.2 \mathrm{ml}$. absolute ethanol; $375 \mathrm{mg}$. polyvinyl pyrrolidone; and distilled water to yield a final volume of $5 \mathrm{ml}$.

The whole retina without a pigment epithelium was then fixed in absolute ethanol. After dehydration, paraffin embedding, and sectioning $(2 \mu-8 \mu)$, the tissue was stained by means of the periodic acid-Schiff technique for glycogen. The retina of the fellow eye was incubated in a medium from which UDPG was omitted. Control sections were stained for glycogen with and without incubation with salivary amylase. 


\section{Results}

Strong lactic dehydrogenase activity was noted in the outer plexiform layer, the inner segment of visual cells, and the pigment epithelium. Lesser activity was present in the inner plexiform, ganglion cell, and nerve fibre layers. In the inner nuclear layer fine, vertical fibres were showing activity.

Strong succinic dehydrogenase activity was noted in the inner segment of the visual cells, and lesser activity in the pigment epithelium, outer plexiform, inner plexiform, ganglion cell, and nerve fibre layers. The localization of malic dehydrogenase was similar to that of succinic dehydrogenase, but the reaction was more marked.

There was marked DPN diaphorase activity in the inner segment of visual cells and lesser activity in the pigment epithelium, plexiform, ganglion cell, and nerve fibre layers.

No difference was observed in the distribution and activity of these dehydrogenases in the normal and diabetic rat retinae.

In the study of the uridine diphosphate glucose glycogen transferase system, there was a marked variation in the synthesis of glycogen not only in different animals but in different portions of the retina of the same animal. The region of the cut edges of the tissue often showed much glycogen which was thought to be induced by damage to the cells.

In the normal and diabetic rat, a few, fine synthesized glycogen granules were observed in the inner segments of the visual cells, but not in the outer segments. The outer nuclear layer and external limiting membrane showed no synthesis of glycogen, but a few, fine synthesized granules of glycogen were arranged vertically. The outer plexiform layer had a slight to moderate amount of glycogen. Synthesis of glycogen was seen in the cytoplasm of some cells or between the cells of the inner nuclear layer. The inner plexiform layer showed glycogen, but the strongly reactive zone observed in the middle layer with phosphorylase, was not present. In the ganglion cell layer, synthesized glycogen granules were often present in the cytoplasm of the ganglion cells. Synthesis of glycogen was observed in the nerve fibre layer, on the internal limiting membrane, and occasionally in retinal capillary walls.

The distribution of synthesized glycogen in the alloxan-diabetic rat retina was similar to that in normal rat retina. The intensity of the reaction in the diabetic rat retina tended to be more marked in the inner retinal layers, but an unequivocal increase in transferase activity could not be demonstrated.

No glycogen transferase activity was demonstrated in the retinae and livers of normal rats or rabbits treated with amylase for 15-60 minutes before incubation. This suggests the possibility that native glycogen may act as a primer for enzyme activity although the distribution of the synthesized glycogen does not parallel the distribution of native glycogen. 


\section{Discussion}

The possible value of an investigation of the distribution of the enzymes of carbohydrate metabolism in the diabetic retina was stated by Ashton (1959) in the Walter Wright lecture:

\footnotetext{
"In the metabolic defect of diabetes the retina, being so particularly dependent upon the breakdown of glucose as an energy source and having a higher glycolytic rate than almost any other tissue, is subject to a chronic metabolic disturbance leading gradually to failure of osmoregulation with the imbibition of water and an increase in retinal turgescence. The resulting rise in tissue tension impedes the capillary circulation, stagnation and anoxia result, and micro-aneurysms form ...".
}

The dehydrogenase studies herein reported indicate a high oxidative capacity of the retina via the glycolytic pathway (lactic dehydrogenase), but no demonstrable difference between the normal and alloxan-diabetic animal. This suggests that, under the conditions of this study, there is no abnormality in this end-step of anaerobic glycolysis which begins with glycogen and ends with lactic acid. However, this pathway is probably not normally activated in the retina and it is unlikely that even if an abnormality was demonstrated it would be of significance in the aetiology of diabetic retinopathy.

Succinic and malic dehydrogenases participate in the sequential removal of hydrogen atoms in the tricarboxylic acid cycle. There is a marked increase in succinic dehydrogenase activity in the liver of diabetic rats (Wollman and Scow, 1951). We have confirmed this observation using histochemical techniques in both the liver and the kidney of alloxan-diabetic rats. However, we have been unable to demonstrate an abnormality in the diabetic retina. This suggests that there is no abnormality in tricarboxylic acid cycle of the diabetic rat retina.

DPN diaphorase is an electron carrier with considerable activity in the system in which DPN ${ }^{+}$is reduced by the lactic-pyruvic system in the presence of lactic dehydrogenase. Its similar distribution in both diabetic and normal animals is not unexpected in view of the comparable results with lactic dehydrogenase.

The increased phosphorylase activity previously demonstrated in the diabetic rat retina by Kurimoto and Newell (1963), together with increased glycogen, stimulated interest in the uridine diphosphate glucose glycogen transferase system. Phosphorylase is an enzyme which in conjunction with the debranching enzyme (amylo-1, 6-glucosidase) catalyses the reversible reaction of glycogen with inorganic phosphate to yield glucose-1-phosphate. In vivo the reaction is mainly in the direction of degradation of glycogen.

Glycogen is synthesized in the body in a reaction beginning with glucose-1phosphate which is converted to uridine diphosphate glucose (UDPG) and then to glycogen in reactions catalysed by the enzyme UDPG glycogen transferase, and the branching enzyme (amylo-1, $4 \rightarrow 1,6$ transglucosidase). 
Using cryostat sections, it was possible to demonstrate UDPG glycogen transferase in the ocular recti muscles, but not in the retina. Thus, in the current study, large portions of the retina were placed in the incubating media for 3 to 6 hours before sectioning. This led to autolytic changes on occasion and sections were not consistently satisfactory. However, no unequivocal abnormality in glycogen synthesis could be demonstrated in the alloxan-diabetic rat when UDPG was used as a substrate.

These findings suggest that alloxan-diabetes in the rat leads to glycogen storage in the retina without increased activity demonstrable in the enzyme responsible for its synthesis, but with markedly increased activity of the enzyme necessary for its degradation.

The various opinions concerning the role of glycogen in retinal metabolism have recently been summarized (Kurimoto and Newell, 1963). In general, glycogen accumulation is an anatomic indicator of a deranged carbohydrate metabolism in alloxan-diabetes which probably reflects the hyperglycaemia. The synthesis of glycogen in the retina is being quantitated in current studies.

A possible explanation of the failure to demonstrate increased activity of UDPG glycogen transferase is the repression of enzyme activity by the products of the reaction as demonstrated by Gorini and Maas (1958). Thus, the presence of excess glycogen would tend to repress activity of UDPG glycogen transferase and stimulate phosphorylase activity.

\section{Summary}

Histochemical studies of the alloxan-diabetic rat indicated no abnormality of activity of lactic, succinic, and malic dehydrogenase, DPN diaphorase, or UDPG glycogen transferase.

\section{REFERENCES}

Ashton, N. (1959). Lancet, 2, 625.

DeRoetTh, A. Jr., and PeI, Y. F. (1960). A.M.A. Arch. Ophthal., 63, 226.

GORINI, L., and MAAS, W. K. (1958). In "A Symposium on the Chemical Basis of Development", ed. W. D. McElroy and B. Glass, p. 469. Johns Hopkins Press, Baltimore.

Heath, H., RutTer, A. C., and BeCK, C. (1962). Vision Res., 2, 33.

ILLING, E. K. B., and GraY, C. H. (1951). J. Endocr., 7, 242.

KorNBLUETH, W., YARDENI-YARON, E., and WerTheIMER, E. (1953). A.M.A. Arch. Ophthal., 50, 500 .

KURIMOTO, S., and NeWELL, F. W. (1963). Invest. Ophthal., $2,24$.

LOWRY, O. H., RoBeRTS, N. R., and LeWIS, C. (1956). J. biol. Chem., 220, 879.

, SchulZ, D. W., Clow, J. E., and Clark, J. R. (1961). Ibid., 236, 2813.

Wollman, S. H., and Scow, R. O. (1951). Endocrinology, 49, 105. 